\title{
Reforms will ease patenting of biotechnology therapeutics
}

In a widely applauded move late last year, the US Commissioner of Patents and Trademarks, Bruce A. Lehman, announced new guidelines to streamline the review of biotechnology patent applications. Companies trying to obtain patent protection for new therapeutic products will no longer need to provide preliminary but costly clinical evidence indicating a product will be effective. Other reforms include a move to allow the filing of applications in electronic form, the development of a more highly educated and better managed staff to review applications, and changes in the patent term that extend their lifetimes from the date of filing to 20 years, which
Bruce Lehman, US patent commissioner. ful. "Some patent examiners were making technical critiques and formally applying standards that seemed more appropriate for the peer-review process for a grant review or to publish a journal article," says Reid Adler, an attorney with Morrison and Foerster in Washington, DC, and former head of the Office of Technology Transfer at the US National Institutes of Health. "The standards required by the Food and Drug Administration for clinical trials or for medical journals to publish papers are simply not appropriate for judging patentability."

Those demands from patent examiners for early and convincing clinical data sometimes led to a 'catch 22 ' for biotechnolis in keeping with international practices.

Critics of the US Patent and Trademark Office say that during the past five years or more some patent examiners were imposing a burdensome requirement for clinical information, insisting data from clinical trials had to be furnished to satisfy the utility clause in the US patent law. Industry representatives, particularly members of the Biotechnology Industry Organization in Washington, DC, helped to persuade Lehman and other patent office officials that reforms were needed.

US law specifies that a patentable invention must meet several general criteria, including novelty, non-obviousness and utility. The standards applied for this third criterion, particularly in the realm of biomedicine, traditionally have been malleable. Typically, it has not been necessary for an applicant to prove that a potential drug actually worked in patients but only to show that a specified clinical use is plausible. Historically, demonstrating a plausible biological activity in an animal model of a disease or in an in vitro reaction was considered adequate proof of utility by the patent office.

Then, during the past five to ten years when a flood of biotechnology applications began arriving at the patent office, some patent examiners discounted the utility claims being made in many applications and called for firmer proof that biotechnology inventions would be use- ogy companies, Lehman admits. That is, companies "were required to provide human clinical data to support an asserted therapeutic utility while being unable to raise funds to perform those trials because their patent situation was unclear." Moreover, he adds: "This is not some esoteric area of the law. It's a vital part of the US economy. Patents give innovators the ability to get the investment money they need to drive new technology forward."

"This 'catch 22' situation of being required to submit clinical data to support patent applications is especially burdensome for small companies," says Lisa Raines of Genzyme Corporation, a biotechnology company with headquarters in Cambridge, Massachusetts, that is developing products for treating rare inherited disorders. Patents are "the life-blood" of companies like Genzyme, she adds, and "we depend on them to get financing."

"It's not the job of the patent office to act as a super medical agency to determine whether products work," points out David Beier, a vice-president of Genentech Inc. in South San Francisco, California. "Safety and efficacy decisions are made by the FDA."

Other elements of this reform, particularly Lehman's commitment to improve the management of the expanding corps of patent examiners and to familiarize them with the law in terms of the new guidelines are also welcome, Adler notes. In recent years, the patent office has been adding staff rapidly to keep pace with the flow of biotechnology applications, and the new staff members often are hired on the basis of their technical training. Indeed, Lehman points with some pride to the fact that more than half of the 165 biotechnology patent examiners now on staff hold PhDs.

"But there was no concomitant training in law to go with this increase in technical expertise," attorney Adler points out. "That helped lead to some of these problems." Beier contends that four elements are vital for strengthening the current system for protecting intellectual property - well-delineated rules for obtaining and enforcing patents, speed of processing applications, adequate scope, and strong validity. The new guidelines address these needs "comprehensively", he says.

JEFFREY L. FOX Freelance writer, Washington, $D C$

\section{Japan to open first AIDS clinic}

As part of Japan's anti-AIDS effort, Tokyo University's Institute of Medical Science will create the country's first clinical department specializing in treatment of the disease. The new AIDS department will be part of the institute's hospital, not its research division, but both clinical care and basic research will be combined. To this end, its staff will be collaborating with laboratories at the institute's research division, which already contains some of Japan's best researchers on AIDS. The new department will be the hub of what is likely to become the country's foremost centre for AIDS research.

The scarcity of institutes that combine clinical treatment with basic research is often seen as a fundamental weakness of the Japanese medical system. In Japan, even senior doctors have heavy clinical workloads and are seldom involved in basic research. It is partly for this reason that Tokyo University looked abroad for its new department head. In December, the institute's professors chose Chikao Morimoto, a Japanese associate professor at the Dana-Farber Cancer Institute in Boston, which is affiliated with Harvard Medical School.

Morimoto's appointment is not without some controversy. During his 15 years at 